\title{
Opportunistic autoimmune disorders potentiated by immune-checkpoint inhibitors anti-CTLA-4 and anti-PD-1
}

\author{
Yi-chi M. Kong ${ }^{1}{ }^{*}$ and Jeffrey C. Flynn ${ }^{2}$ \\ ${ }^{1}$ Department of Immunology and Microbiology, Wayne State University School of Medicine, Detroit, MI, USA \\ ${ }^{2}$ Department of Orthopaedic Surgery, Providence Hospital and Medical Centers, Southfield, MI, USA
}

\section{Edited by:}

Fang-Ping Huang, Imperial College London, UK

Reviewed by:

Christopher E. Rudd, University of Cambridge, UK

José Mordoh, Fundación Instituto Leloir, Argentina

Julian Pardo, Fundación Agencia

Aragonesa para la Investigación y el

Desarrollo, Spain

*Correspondence:

Yi-chi M. Kong, Department of Immunology and Microbiology,

Wayne State University School of Medicine, 540 E. Canfield Avenue,

Detroit, MI 48201, USA

e-mail:ykong@med.wayne.edu
To improve the efficacy of immunotherapy for cancer and autoimmune diseases, recent ongoing and completed clinical trials have focused on specific targets to redirect the immune network toward eradicating a variety of tumors and ameliorating the selfdestructive process. In a previous review, both systemic immunomodulators and monoclonal antibodies (mAbs), anti-CTLA-4, and anti-CD52, were discussed regarding therapeutics and autoimmune sequelae, as well as predisposing factors known to exacerbate immune-related adverse events (irAEs). This review will focus on immune-checkpoint inhibitors, and the data from most clinical trials involve blockade with anti-CTLA-4 such as ipilimumab. However, despite the mild to severe irAEs observed with ipilimumab in 60\% of patients, overall survival (OS) averaged $\sim 22-25 \%$ at 3-5 years. To boost OS, other mAbs targeting programed death-1 and its ligand are undergoing clinical trials as monotherapy or dual therapy with anti-CTLA-4. Therapeutic combinations may generate different spectrum of opportunistic autoimmune disorders. To simulate clinical scenarios, we have applied regulatory $T$ cell perturbation to murine models combined to examine the balance between thyroid autoimmunity and tumor-specific immunity.

\section{Keywords: anti-CTLA-4, anti-PD-1, autoimmune disease, tumor immunity, immune-checkpoint inhibitor}

\section{INTRODUCTION}

In recent decades, cancer therapy has focused on amplifying the immune system to bolster the host's anti-tumor response. Utilizing systemic immunomodulators, monoclonal antibodies (mAbs), and stem cell transplantation, progress has been rapid in prolonging survival. However, targeted immunotherapy has come with a price; altered immunoregulation provoking immune dysfunction has opened the door to opportunistic autoimmune disorders. Previously, both systemic immunomodulators and mAbs, antiCTLA-4 and anti-CD52, were discussed in terms of therapeutic usage, autoimmune sequelae, and important predisposing factors, e.g., HLA class II genes and gender predilection, known to influence immune-related adverse events (irAEs) (1). Similar and additional immunotherapeutic modalities associated with autoimmunity, particularly thyroid dysfunction, were likewise highlighted by others $(2,3)$. In addition to CTLA-4, a number of immune-checkpoints are also being targeted in cancer immunotherapy. Thus far, the most information has come from longer and larger clinical trials with anti-CTLA-4 (ipilimumab and tremelimumab), accompanied by mild to severe irAEs (4-6). In early trials, it was hoped that irAEs could serve as a predictor of improving anti-CTLA-4 immunotherapy $(7,8)$. However, analysis of 139 metastatic melanoma patients given ipilimumab revealed that the frequency of irAEs after a 2-4 year follow-up was $81 \%$ with a total response rate of $17 \%$ (23 of 139) (7); of the 86 patients with irAEs, $74 \%$ (64 of 86) showed no objective improvement (1).

Thus, targeting CTLA-4, a T cell regulatory molecule, impacts on its two primary functions in the immune network: (1) Its upregulation during a $\mathrm{T}$ cell-mediated response serves as a negative regulator by engaging the $\mathrm{B} 7$ family costimulatory molecules on antigen-presenting cells with higher avidity than CD28 (9); and (2) Its constitutive expression on regulatory T cells (Tregs) is critical to the Foxp3 function in suppressing autoreactive $T$ cell activation $(10,11)$. ctla $^{-/-}$mice develop severe multiorgan autoimmunity, indicative of deficiency in both these functions $(12,13)$. When humanized CTLA- 4 mAbs were first used to treat advanced melanoma a decade ago, the major goal was to interfere with the negative signaling of an ongoing anti-tumor response discernible in many patients $(4,6)$. However, since a key role of CTLA-4 is to enable Treg suppression of autoreactive T cell activation at the costimulatory level of DC $(10,11)$, it was no surprise that opportunistic autoimmune disorders surfaced as prominent irAEs from CTLA-4 blockade. The variety stems from the everpresent autoantigens and autoreactive $\mathrm{T}$ cells unleashed from self tolerance regulation (1). For example, in our tolerance induction study in murine experimental autoimmune thyroiditis (EAT), a model for the prevalent Hashimoto's thyroiditis (14), co-injection of anti-CTLA- 4 with the autoantigen, thyroglobulin $(\mathrm{Tg})$, interfered with activation of naturally existing $\mathrm{CD} 4{ }^{+} \mathrm{CD} 25^{+} \mathrm{Foxp}^{+}$ Tregs (nTregs); the mice developed thyroiditis, mimicking a major clinical autoimmune sequela (15).

Using revised assessment criteria including overall survival (OS) in phase II/III trials to take into account the longer survival kinetics for ipilimumab (16), recent compilation of ipilimumab phase I/II trial results showed a range of $12-36 \%$ OS at 3-5 years, with variables including the dose, patient number, prior, or adjunct treatment (4). Pooling phase II/III trials 
showed irAEs approximating 60\% with less severe grade 3-4 in the phase III trials, likely due to earlier recognition and management of autoimmune sequelae $(4,17)$. While the percentages of irAEs varied, most included skin rashes, colitis, thyroid dysfunction, hypophysitis, hepatitis, and pancreatitis $(4,17)$, as also reported in western Europe (5). Treatment-related deaths continued to occur and severe morbidity required stringent life-long treatment and hormonal supplementation $(4,5)$. The second $\mathrm{mAb}$, tremelimumab, likewise underwent phase I/II trials [see Ref. (1)] and phase III trials with similar irAEs but less durable OS than with ipilimumab; in fact, survival was not much longer than after standard chemotherapy with temozolomide or dacarbazine (6). To boost OS, mAbs that blockade the function of another immune-checkpoint, programed death-1 (PD-1), or its ligand (PD-L1), have been undergoing clinical trials as monotherapy or dual therapy with anti-CTLA-4.

\section{MODELS TO PROBE THE BALANCE BETWEEN AUTOIMMUNITY AND TUMOR IMMUNITY UPON Treg PERTURBATION}

The high percentages of irAEs from anti-CTLA- 4 therapy clearly show that maintenance of Treg function and self tolerance constitutes a premier CTLA-4 function. Autoimmune thyroid disease, including Hashimoto's thyroiditis and Graves' disease, represents the most prevalent autoimmune condition (18), and CTLA-4 blockade has joined other systemic immunomodulators [e.g., interferon- $\alpha,-\beta$, interleukin (IL)-2] and leukocyte-target agents (e.g., anti-CD52) in triggering thyroid dysfunction $(1,3,19,20)$. As EAT has long served as a model to study Treg function in self tolerance to mouse $\operatorname{Tg}(14,21,22)$, we developed in recent years four murine models combining EAT and breast cancer vaccine protocols under Treg perturbation and MHC class II gene influence, using autoimmune thyroiditis as a sequela indicator (23).

The first three utilized well-established tumor models in wild type mice or mice transgenic for Her-2/neu breast cancer antigen, which harbor class II-linked, EAT-resistant haplotype $\left(H 2^{d}\right.$ or $\left.H 2^{b}\right)$. In the first model, we induced EAT concurrently with anti-tumor immunity in wild type mice at the time of Treg depletion with mAb to CD25 (24). Treg depletion enhanced tumor regression and thyroiditis. Immune responses to neu and mouse Tg were greater than control groups given tumor or Tg alone, indicating that ongoing tumor regression and autoimmune response provided additional mutual stimuli. In the second model, we used rat neu-transgenic mice, which required both Treg depletion and neu DNA vaccination to develop resistance to tumor challenge and spontaneous tumorigenesis (25). Mutual stimulation during responses to neu and mouse $\mathrm{Tg}$ was again observed. In tumorregressing mice, there were significant increases in interferon$\gamma$-producing $\mathrm{T}$ cells and greater thyroid destruction even in the EAT-resistant strain. Lastly, in the third model, we introduced the HLA-DR3 transgene, an EAT-susceptible allele (26), and an Her-2 transgene into EAT-resistant $H 2 A^{b}$ mice to determine if anti-tumor response was independent of EAT susceptibility. $\left(A^{b}\right.$ Her-2xDR3) $\mathrm{F}_{1}$ mice expressed both $\mathrm{A}^{\mathrm{b}}$ and DR3 and were tolerant to both Tg and Her-2 (27). After Treg depletion followed by Her2 DNA and mouse Tg injections, tumor rejection was similar in
Her-2 transgenic mice expressing either $\mathrm{A}^{\mathrm{b}}$ or $\mathrm{A}^{\mathrm{b}} / \mathrm{DR} 3$, but thyroiditis was augmented only in $\left(A^{b} / \mathrm{DR} 3\right) \mathrm{F}_{1}$ mice, showing that Her-2 immunity, unlike autoimmunity, was independent of DR3 expression.

In the fourth combined model, we used an EAT-susceptible CBA/J $\left(H 2^{k}\right)$ haplotype with demonstrated antigen-specific nTregmediated tolerance. Depleting pre-existing nTregs markedly enhanced thyroiditis development with soluble mouse Tg even without adjuvant (15). Control mice with nTregs, which had been activated/expanded after exposure to mouse Tg by either injection or physiologic release (via thyroid-stimulating hormone infusion in an osmotic pump), withstood EAT induction with mouse Tg plus adjuvant $(22,28)$. In contrast, nTreg-depleted mice were incapable of establishing this strong and long-lasting tolerance $(14,15,22)$. For the cancer portion, CBA/J tumor was derived from a spontaneous mammary adenocarcinoma line, and resistance to lethal challenge was instilled by prior Treg depletion and vaccination with irradiated tumor cells (23). To simulate patients with MHC class II-associated predisposition to autoimmunity and subjected to immune targeting, mouse $\mathrm{Tg}$ was also given. Treg depletion not only augmented tumor immunity but also thyroidal infiltration (29). Furthermore, to simulate the scenario in some cancer patients with pre-existing autoimmunity and given immunotherapy, mice were pretreated with mouse $\mathrm{Tg}+$ low doses of IL-1 to establish a subclinical, mild thyroiditis condition. Treg depletion, tumor vaccination, and mouse $\mathrm{Tg}$ injections then followed. While anti-tumor immunity remained unchanged, thyroiditis was exacerbated (29). Thus, this recent model takes into account genetically predisposed patients who have no underlying thyroid dysfunction or have pre-existing, undiagnosed disease.

\section{TARGETING CTLA-4 LED TO UNUSUAL SPECTRUM OF AUTOIMMUNE SEQUELAE}

In murine EAT, tolerance induction with the known autoantigen, mouse Tg, and its blockade of nTreg activation by anti-CTLA4 to allow thyroiditis development can be followed with timed co-administration (15). However, in cancer patients, there are multiple self antigens for which the maintenance mechanisms of self tolerance can be disrupted with anti-CTLA- 4 therapy at varying doses and intervals, resulting in unpredictable manifestations of $20-60 \%$ of irAEs with grade $1-4$ severity. In addition to advanced melanoma, both ipilimumab and tremelimumab have been used to treat other solid tumors and hematologic cancers and the frequent irAEs have included dermatitis, enterocolitis, hepatitis, thyroid dysfunction, and hypophysitis with widespread endocrinopathies, irrespective of cancer types (3-6, $19,20)$. Although these autoimmune diseases are primarily organspecific, T cell-mediated, and with mononuclear cell infiltration of the specific organ, plasma cells may be seen with time. Moreover, when several organs are involved with attendant proinflammatory cytokines, irAEs may become exacerbated and more widespread. Thus, different irAEs often occur throughout the treatment period and beyond.

There is agreement that the extent of severe irAEs is dosedependent, but OS improvement generally does not correspond 
linearly with dosage (5), nor correlates with severity of irAEs $(1,19)$. Torino et al. (19) undertook an in-depth analysis of endocrine dysfunction for 21 phase I-III trials with ipilimumab treatment of melanoma and several other solid tumors. The primary emphasis was on hypophysitis of grades 3-4, but the involvement of other endocrine dysfunctions (hypothyroidism, adrenal insufficiency) and other common irAEs (e.g., diarrhea, colitis/enterocolitis, dermatitis, hepatitis, and arthritis) was also included. A more recent report by some of the same authors, Corsello et al. (20), extended the analysis to 28 trials, subcategorizing classifiable endocrine disorders and other common irAEs, which may or may not be autoimmune in origin. As mentioned above, since irAEs generally involved up to $60 \%$ of patients, at $2-$ $3 \times$ the OS, a direct correlation of OS with irAE would be difficult at this time (4).

As discussed earlier (1), while the increase in thyroid dysfunction could have been anticipated, given the high prevalence in the general population, the most unusual and distinct association with anti-CTLA-4 therapy is autoimmune hypophysitis, with an incidence of 3-9\% in early trials far exceeding its rare occurrence ( $\sim 1$ in 0.5 million) $(19,30)$. Another early melanoma trial with ipilimumab reported $17 \%$ (8 of 46) (31). The analyses of clinical trials with ipilimumab and tremelimumab gave an average of $\sim 4 \%$ hypophysitis, closely rivaling hypothyroidism (19, 20). While hypothyroidism is $5-6 \times$ more prevalent in females in Caucasians (18), thus far hypophysitis from anti-CTLA-4 therapy has occurred mostly in males, in part influenced by the ratio of female:male of $\sim 1: 2$ in melanoma patients. Other genetic (HLA, CTLA-4 gene polymorphism, mutations) and environmental factors may also take part $(1,4,32)$. The high incidence of hypophysitis, its need for early corticosteroid intervention and life-long hormonal replacement prompted the advocacy of early recognition and management, together with thyroid function tests (17, 19, 20). Searches for specific pituitary antigens for early antibody detection to replace immunofluorescence on pituitary sections are ongoing (33-35).

Although autoimmune sequelae (e.g., hypophysitis, thyroid dysfunction, and hormonal imbalance) are gaining recognition, the high incidences of colitis and dermatitis have not been investigated as to culprit antigens, which could be self, commensally microbial, or tumor-associated. A recent survey of anti-CTLA-4 therapy in 752 melanoma patients at 19 skin centers in western Europe excluded colitis and dermatitis from the usually observed $60 \%$ irAEs $(4,5)$, and concentrated on raising awareness to rare yet severe toxicities, some of which may be related to prior chemo- or radio-therapy. A total of 88 irAEs from 82 of $752(11 \%)$ patients were tabulated, 12 with hypophysitis (5). With melanoma patients, the side effects of vitiligo and uveitis were often noted because of shared melanocyte antigens, often aggravated by vaccination $(1,5)$. The 15 rarer cases included gastric problems, ischemia and bowel perforations, fatal hepatitis, hypophysitis with brain edema, and inflammation of the central nervous system. There were also respiratory and cardiac problems. Thus, the untoward autoimmune disorders are opportunistic and unpredictable, as well as far-reaching.

\section{SPECIFIC ANTIGENS TO BOOST TUMOR IMMUNITY AND MONITOR Treg ACTIVITY}

As seen above, the weakly immunogenic, tumor-associated antigens, which can be overexpressed self, altered self, or neoantigens, are further interwoven with unexpected pathogenic autoantigens during CTLA-4 blockade. Examination of tumor infiltrates after tremelimumab therapy revealed an increase in activated $\mathrm{CD}^{+} \mathrm{T}$ cells in many melanoma patients; while not Tregs, this non-specific increase was observed in a greater proportion of patients than patients deriving any clinical benefit and showed no correlation with either tumor progression or regression (36). In phase II trials of melanoma patients with ipilimumab, a peripheral increase in the $\% \mathrm{CD}^{+}$and $\% \mathrm{CD}^{+}$activated $\mathrm{T}$ cells, but not those with a Treg phenotype, was noted (37). Of interest was the greater serologic reactivity to several melanoma antigens and a cancer-testis antigen NY-ESO-1. Because NY-ESO-1 is expressed in a number of solid tumors and $30-40 \%$ of advanced melanoma patients, it has been examined as a specific biomarker for increased T and B cell reactivity after CTLA-4 blockade, and if such reactivities could be associated with positive clinical outcome (37-40). While an increase in anti-NY-ESO-1 has often been detected, its association with positive benefit is still controversial (38-40). However, it appeared that clinical benefit could be associated with NY-ESO-1 reactivity if both antibody and $\mathrm{CD}^{+} \mathrm{T}$ cells were considered in concert (10 of 13 or $77 \%$ ) (39). More such studies will be needed to determine if specific reactivity to NY-ESO-1 as well as other melanoma peptides has a predictive value. Meanwhile, to increase the efficacy of CTLA-4 blockade and detect changes in tumor-specific effector $\mathrm{T}$ cells, therapeutic vaccines are being incorporated. In a large phase III trial (41), a gp100 peptide vaccine was given with ipilimumab (403 patients), compared to ipilimumab (137) or gp100 (136) alone. However, there was no significant increase in OS provided by including gp100 vaccination, compared to ipilimumab alone.

Detecting antigen-specific effector T cells is complicated by the presence of Tregs. In the tumor microenvironment, induced Tregs (iTregs) represent a major component of suppressor cell subsets and, as opposed to nTregs, usually arise or are converted from naive $\mathrm{T}$ cells in response to antigenic stimulus plus local TGF$\beta$ and IL-10 production (42). Intratumoral iTregs often exist in greater percentages than in the periphery. Although in murine melanoma studies Fc-dependent ADCC-like depletion of Tregs was demonstrable upon anti-CTLA treatment (43), the frequent detection of intratumoral iTregs in the human suggests that this kind of depletion might be an adjunct to improved clinical benefit. But the challenge remains to identify whether the effect was on tumor-specific iTregs, so as to monitor and inhibit their suppressor role (44). Following therapeutic vaccination, multiple peptides have been used to monitor iTreg activity. In one phase II trial in renal cell cancer patients, cyclophosphamide, known to deplete Tregs (22), was given before the IMA901 vaccine, consisting of multiple tumor-associated peptides used to demonstrate heightened $\mathrm{T}$ cell responses (45). In another study, synthetic peptides were used to compare the repertoire of tumor-specific iTregs and effector $\mathrm{T}$ cells in colorectal carcinoma patients (46). While 
differences were noted between the two populations, the suppressor activity was shown to stem from iTregs that shared the same repertoire as effector $\mathrm{T}$ cells. Additional studies have made use of class II tetramers to monitor antigen specificity. After vaccination of melanoma patients with HLA-A2-restricted Melan-A peptide, monitoring with HLA-DQ6-restricted Melan-A peptide multimers revealed a downshift in specific Tregs with increased effector $\mathrm{T}$ cell responses (47). In breast cancer patients, tetramers from HLA-DR4-, DR7-restricted mammaglobin peptides were used to detect iTregs in the periphery (48). After their depletion in vitro, effector $\mathrm{T}$ cell responses to several mammaglobin peptides increased. Thus, antigenic specificity, if known, could aid assessment of immunotherapeutic efficacy.

\section{PD-1 AND PD-L1 BLOCKADE TO AUGMENT TUMOR IMMUNITY}

Recent reviews have discussed in depth the phenomenon of $\mathrm{T}$ cell exhaustion, where activated T cells highly expressing PD-1, as exemplified by virus-specific $\mathrm{CD}^{+}$cells, exhibited exhaustion phenotypes and failed to combat chronic infections (49-51). In the tumor microenvironment, PD-1 expression was found on impaired infiltrating lymphocytes (52) and Tregs (53). Its major ligand, PD-L1, has been found on multiple epithelial carcinomas, compared to PD-L2 on lymphoid tumors associated with its expression pattern (49-51). There is no clear consensus on whether PD-L1 expression by tumors is associated with greater objective response from PD-1 blockade; more specific staining reagents have led to reports of positive association $(54,55)$. PD-1 is also expressed on activated $\mathrm{B}, \mathrm{NK}$, and NKT cells and is involved in down-regulating autoimmunity. PD-1-deficient C57BL/6 mice exhibited lupus-like arthritis and glomerulonephritis (56), and PD-1-deficient BALB/c mice developed cardiomyopathy from an autoantibody to cardiac troponin 1 (57). Thus, these autoimmune syndromes have a strong pathogenic autoantibody component. While preclinical tumor models have shown clinical benefit with PD-1 blockade, it is uncertain if only activated $\mathrm{CD}^{+}$cells participated in the OS (50).

Two phase I, ongoing dose-escalation trials have been reported with two IgG4 mAbs to PD-1. Lambrolizumab (MK-3475), which has recently been designated by the FDA as a "breakthrough therapy" drug to treat advanced melanoma (58), was used to treat 135 melanoma patients, who were evaluated for up to 70 weeks (59). The confirmed response rate was 38\% (44 of 117), irrespective of prior ipilimumab treatment, and appeared dose-dependent. Biopsies of regressing lesions revealed densely infiltrated $\mathrm{CD}^{+} \mathrm{T}$ cells. irAEs were 79\% (107 of 135); 17 of the 107 had grade 3-4. Beside skin and gastrointestinal problems, hypothyroidism was $8 \%$. The second phase I trial with nivolumab (BMS-936558) included 296 patients with melanoma, non-small cell lung cancer, prostate cancer, renal cell, or colorectal cancer. The first report in 2012 was after $\sim 1$ year and the objective response averaged $\sim 20-25 \%$ (55). Grade 3-4 irAEs were observed in 14\% (41 of 296), of which $11 \%$ were considered serious; 15 patients discontinued the study and 3 deaths $(1 \%)$ were attributed to pneumonitis. The spectrum of irAEs was mostly similar to lambrolizumab therapy (59). But with twice the number of patients, the variety of irAEs resembled those seen with ipilimumab, albeit at lower overall percentages. The spectrum was dose-dependent and included rash, pruritus, and diarrhea (all at $\sim 27 \%$ ), with hyperthyroidism and hypothyroidism at $3-7 \%$ (55). An exception to the ipilimumab treatment was the prominent pulmonary toxicities seen in $2-4 \%$ of patients $(55,59)$. In addition to fatalities $(55)$, the $2-4 \%$ in phase I trials were of grade $3-4(55,59)$. A recent report about ongoing phase II/III trials also listed pneumonitis as a notable side effect (60). Whether it is autoimmune in origin is undetermined. An updated analysis on 107 melanoma patients treated with nivolumab showed $40 \%$ OS at 3 years (61).

Another multicenter phase I trial enrolled 207 patients without prior experience with CTLA-4, PD-1, or PD-L1 mAb, who were given anti-PD-L1 (IgG4, BMS-936559) for a number of solid tumors for up to 2 years (62). The durable response rate was $6-17 \%$. Treatment-related adverse events were noted in $61 \%$ (126 of 207), and 39\% (81 of 207) were considered irAEs; these patients have a somewhat different spectrum and a lower percentage of irAEs compared to patients in the anti-PD-1 trials. Because these investigators were also conducting the phase I trial with nivolumab (55), their initial clinical impression was that antiPD-L1 blockade was inferior to anti-PD-1 in achieving objective responses (62).

Interestingly, pneumonitis was not a noted side effect in the anti-PD-L1 phase I trials $(60,62)$, but the $39 \%$ irAEs showed a distinct autoimmune-related trend: rash, hypothyroidism, hepatitis, plus isolated cases of diabetes mellitus, and myasthenia gravis, all mostly of grade 1-2 (62). PD-1 binds to both PDL1 (broad tissue distribution) and PD-L2 (limited primarily to DCs) $(63,64)$. Since lung tissues express PD-L1 and contain activated alveolar macrophages, it is possible that anti-PD- 1 blockade removes the inhibitory signals that control tissue proliferation and cytokine production more so in the lung, resulting in pneumonitis, whereas anti-PD-L1 blockade does not block the immune-checkpoint between PD-1 and PD-L2. Another possibility is that, since self tolerance is maintained by the continuing interaction between PD-1 and PD-L1 to prevent TCRdriven signaling (65), upon anti-PD-L1 blockade, autoreactive $\mathrm{T}$ cells could become activated resulting in the autoimmune syndromes reported.

\section{COMBINING IMMUNE-CHECKPOINT INHIBITORS COULD POTENTIATE AUTOIMMUNE SEQUELAE}

There are multiple national clinical trials planned or ongoing with ipilimumab plus chemo- or radio-therapeutic agents, cytokines (e.g., GM-CSF, IL-2, IL-21), and other systemic immunomodulators, most with the goal of stimulating the effector $\mathrm{T}$ cell arm with some targeting dendritic and B cells also [see Ref. (51)]. Because anti-CTLA inhibited Treg function and potentiated irAEs, the use of low dose cyclophosphamide could further target nTregs (22, 45 ) and increase autoimmune sequelae, similar to Treg-depleting anti-CD52 (1). In murine models of B16 melanoma tumors (66) and CT26 colon and ID8-VEGF ovarian carcinomas (67), dual blockade of CTLA-4 and PD-1 enhanced greater tumor rejection than each alone. It should be noted that, unlike in clinical trials, these tumors were manipulated to express GM-CSF, as was 
Table 1 | Function of CTLA-4 and PD-1 in the immune network and the impact of immune-checkpoint inhibitors anti-CTLA-4 and/or anti-PD-1 on examples of tumor immunity and autoimmunity.

\begin{tabular}{ll} 
Functions & Consequences \\
& \\
\hline $\begin{array}{l}\text { CTLA-4 upregulation on } \\
\text { APCs/peptide-stimulated Tregs }\end{array}$ & $\begin{array}{l}\text { Suppresses priming of } \\
\text { naive/autoreactive T cells and } \\
\text { downmodulates B7-1/B7-2 on APCs }\end{array}$ \\
$\begin{array}{ll}\text { maintains peripheral tolerance } \\
\text { CTLA-4 binding to B7-1 and B7-2 causes }\end{array}$ & $\begin{array}{l}\text { Activation of the tryptophan- } \\
\text { catabolizing enzyme indoleamine } \\
\text { 2,3-dioxygenase inhibits T cell } \\
\text { priming and proliferation }\end{array}$
\end{tabular}

CTLA-4 signaling stimulates production of cytokines TGF- $\beta$ and/or IL-10 by Tregs

CTLA-4 upregulation on activated $T$ cells binds to B7-1/B7-2 at high affinity

\begin{abstract}
CTLA-4 signaling alters motility and inhibits T cell receptor-mediated "stop" signal
\end{abstract}

PD-1 signaling enhances Treg function

PD-1 signaling inhibits motility and T cell receptor-mediated "stop" signal

PD-1 upregulation on activated T cells
Inhibits function of APCs and T cells

Negative feedback signaling inhibits continued $\mathrm{T}$ cell proliferation
Leach et al. (69): colon carcinoma Hurwitz et al. (71): prostate cancer

\section{Simpson et al. (43) melanoma \\ Ruocco et al. (74): breast cancer} Reduces efficiency of effector T ce killing and APC interaction

Inhibits T cell priming and maintains self tolerance

Inhibits autoreactive T cell activation and reduces effector $T$ cell function

Inhibits effector T cell function (anergy or exhaustion)

Holmgaard et al. (68): melanoma

Holmgaard et al. (68): melanoma

Ahmadzadeh et al. (52):

Tumor immunity
Holmgaard et al. (68): melanoma
Leach et al. (69): colon carcinoma
Hurwitz et al. (71): prostate
cancer

Liu et al. (75): colitis

Oaks and Hallett (76): AITD

Hurwitz et al. (71): prostatitis

Choi et al. (77): CIA

Hurwitz et al. (78): EAE

Torino et al. (19): clinical

hypophysitis

Morris et al. (15): EAT

diabetes

Kwidzinski et al. (73): EAE
Ansari et al. (72): type I diabetes

Fife et al. (65): type I diabetes

melanoma patients

Wang et al. (53): melanoma

patients

Duraiswamy et al. (67): colon and

ovarian cancers

Curran et al. (66): melanoma
Ansari et al. (72) type I

diabetes

Dual blockade

AITD, human autoimmune thyroid disease; APC, antigen-presenting cell; CIA, collagen-induced arthritis; EAE, experimental autoimmune encephalomyelitis; EAT, experimental autoimmune thyroiditis; iTreg, induced regulatory $T$ cell; Treg, regulatory $T$ cell.

whole cell vaccination included in some experiments. The presence of GM-CSF could influence the expression pattern reported for tumor-infiltrating lymphocytes (67). Table 1 lists the important functions of CTLA- 4 and PD- 1 molecules in maintaining homeostasis of the immune network, and provides examples of the impact of anti-CTLA-4 and/or anti-PD-1 blockade on tumor immunity and autoimmunity.

Since CTLA-4 blockade interferes with peripheral tolerance induction/maintenance and affects primarily the early stages of the immune response, and PD-1 blockade acts toward the late stages at the tissue sites (79) and each can augment OS, dual therapy could further enhance OS, provided that the irAEs are not unreasonably additive. In melanoma patients, a phase I trial combining ipilimumab and nivolumab has begun (80). The need to test different regimens resulted in small patient sizes of 33-53. While the spectrum of irAEs was essentially similar to monotherapy, OS was higher at 24 weeks, based on previous experience.

Longer follow-ups and additional trials will be necessary to assess various parameters affecting irAEs: HLA genotype, environmental and gender influences, and antigen specificities for both Tregs and effector T cells. As seen in our EAT-anti-tumor 
models, subclinical autoimmune conditions (29), and mutual stimulation arising from anti-tumor and autoimmune inflammation also contribute to the overall response enhancing tumor immunity and autoimmunity $(24,25)$. Importantly, there appears to be different pathogenic pathways to autoimmune manifestations, with $\mathrm{PD}$-1-deficiency favoring a pathogenic autoantibody profile and CTLA-4 blockade favoring $\mathrm{T}$ cell-mediated organ damage.

\section{REFERENCES}

1. Kong YM, Wei W-Z, Tomer Y. Opportunistic autoimmune disorders: from immunotherapy to immune dysregulation. Ann N Y Acad Sci (2010) 1183:222-36. doi:10.1111/j.1749-6632.2009.05138.x

2. Amos SM, Duong CP, Westwood JA, Ritchie DS, Junghans RP, Darcy PK, et al. Autoimmunity associated with immunotherapy of cancer. Blood (2011) 118:499-509. doi:10.1182/blood-2011-01-325266

3. Hamnvik OP, Larsen PR, Marqusee E. Thyroid dysfunction from antineoplastic agents. J Natl Cancer Inst (2011) 103:1572-87. doi:10.1093/jnci/djr373

4. Wolchok JD, Hodi FS, Weber JS, Allison JP, Urba WJ, Robert C, et al. Development of ipilimumab: a novel immunotherapeutic approach for the treatment of advanced melanoma. Ann N Y Acad Sci (2013) 1291:1-13. doi:10.1111/nyas. 12180

5. Voskens CJ, Goldinger SM, Loquai C, Robert C, Kaehler KC, Berking C, et al. The price of tumor control: an analysis of rare side effects of anti-CTLA-4 therapy in metastatic melanoma from the ipilimumab network. PLoS One (2013) 8:e53745. doi:10.1371/journal.pone.0053745

6. Ribas A, Kefford R, Marshall MA, Punt CJ, Haanen JB, Marmol M, et al. Phase III randomized clinical trial comparing tremelimumab with standard-ofcare chemotherapy in patients with advanced melanoma. J Clin Oncol (2013) 31:616-22. doi:10.1200/JCO.2012.44.6112

7. Downey SG, Klapper JA, Smith FO, Yang JC, Sherry RM, Royal RE, et al. Prognostic factors related to clinical response in patients with metastatic melanoma treated by CTL-associated antigen-4 blockade. Clin Cancer Res (2007) 13:6681-8. doi:10.1158/1078-0432.ccr-07-0187

8. Beck KE, Blansfield JA, Tran KQ, Feldman AL, Hughes MS, Royal RE, et al. Enterocolitis in patients with cancer after antibody blockade of cytotoxic Tlymphocyte-associated antigen 4. J Clin Oncol (2006) 24:2283-9. doi:10.1200/ jco.2005.04.5716

9. Krummel MF, Allison JP. CD28 and CTLA-4 have opposing effects on the response of T cells to stimulation. J Exp Med (1995) 182:459-65. doi:10.1084/ jem.182.2.459

10. Wing K, Onishi Y, Prieto-Martin P, Yamaguchi T, Miyara M, Fehervari Z, et al. CTLA-4 control over Foxp $3^{+}$regulatory T cell function. Science (2008) 322:271-5. doi:10.1126/science.1160062

11. Sakaguchi S, Miyara M, Constantino CM, Hafler DA. FOXP3+ regulatory T cells in the human immune system. Nat Rev Immunol (2010) 10:490-500. doi:10.1038/nri2785

12. Waterhouse P, Penninger JM, Timms E, Wakeham A, Shahinian A, Lee KP, et al. Lymphoproliferative disorders with early lethality in mice deficient in Ctla-4. Science (1995) 270:985-8. doi:10.1126/science.270.5238.985

13. Tivol EA, Borriello F, Schweitzer AN, Lynch WP, Bluestone JA, Sharpe AH. Loss of CTLA-4 leads to massive lymphoproliferation and fatal multiorgan tissue destruction, revealing a critical negative regulatory role of CTLA-4. Immunity (1995) 3:541-7. doi:10.1016/1074-7613(95)90125-6

14. Kong YM, Morris GP, Brown NK, Yan Y, Flynn JC, David CS. Autoimmune thyroiditis: a model uniquely suited to probe regulatory $\mathrm{T}$ cell function. J Autoimmun (2009) 33:239-46. doi:10.1016/j.jaut.2009.09.004

15. Morris GP, Brown NK, Kong YM. Naturally-existing CD $4^{+} \mathrm{CD} 25^{+}$Foxp $3{ }^{+}$regulatory $\mathrm{T}$ cells are required for tolerance to experimental autoimmune thyroiditis induced by either exogenous or endogenous autoantigen. J Autoimmun (2009) 33:68-76. doi:10.1016/j.jaut.2009.03.010

16. Hoos A, Eggermont AM, Janetzki S, Hodi FS, Ibrahim R, Anderson A, et al. Improved endpoints for cancer immunotherapy trials. J Natl Cancer Inst (2010) 102:1388-97. doi:10.1093/jnci/djq310

17. Weber JS, Kahler KC, Hauschild A. Management of immune-related adverse events and kinetics of response with ipilimumab. J Clin Oncol (2012) 30:2691-7. doi:10.1200/JCO.2012.41.6750
18. Jacobson DL, Gange SJ, Rose NR, Graham NMH. Epidemiology and estimated population burden of selected autoimmune diseases in the United States. Clin Immunol Immunopathol (1997) 84:223-43. doi:10.1006/clin.1997. 4412

19. Torino F, Barnabei A, De VL, Salvatori R, Corsello SM. Hypophysitis induced by monoclonal antibodies to cytotoxic $\mathrm{T}$ lymphocyte antigen 4 : challenges from a new cause of a rare disease. Oncologist (2012) 17:525-35. doi:10.1634/ theoncologist.2011-0404

20. Corsello SM, Barnabei A, Marchetti P, De VL, Salvatori R, Torino F. Endocrine side effects induced by immune checkpoint inhibitors. J Clin Endocrinol Metab (2013) 98:1361-75. doi:10.1210/jc.2012-4075

21. Kong YM, Okayasu I, Giraldo AA, Beisel KW, Sundick RS, Rose NR, et al. Tolerance to thyroglobulin by activating suppressor mechanisms. Ann N Y Acad Sci (1982) 392:191-209. doi:10.1111/j.1749-6632.1982.tb36108.x

22. Kong YM, Giraldo AA, Waldmann H, Cobbold SP, Fuller BE. Resistance to experimental autoimmune thyroiditis: $\mathrm{L} \mathrm{T} 4^{+}$cells as mediators of both thyroglobulin-activated and TSH-induced suppression. Clin Immunol Immunopathol (1989) 51:38-54. doi:10.1016/0090-1229(89)90204-3

23. Kong YM, Jacob JB, Flynn JC, Elliott BE, Wei W-Z. Autoimmune thyroiditis as an indicator of autoimmune sequelae during cancer immunotherapy. Autoimmun Rev (2009) 9:28-33. doi:10.1016/j.autrev.2009.02.034

24. Wei W-Z, Jacob JB, Zielinski JF, Flynn JC, Shim KD, Alsharabi G, et al. Concurrent induction of antitumor immunity and autoimmune thyroiditis in $\mathrm{CD} 4{ }^{+} \mathrm{CD} 25^{+}$regulatory T cell-depleted mice. Cancer Res (2005) 65:8471-8. doi:10.1158/0008-5472.CAN-05-0934

25. Jacob JB, Kong YM, Nalbantoglu I, Snower DP, Wei W-Z. Tumor regression following DNA vaccination and regulatory $\mathrm{T}$ cell depletion in neu transgenic mice leads to an increased risk for autoimmunity. J Immunol (2009) 182:5873-81. doi:10.4049/jimmunol.0804074

26. Kong YM, Lomo LC, Motte RW, Giraldo AA, Baisch J, Strauss G, et al. HLADRB1 polymorphism determines susceptibility to autoimmune thyroiditis in transgenic mice: definitive association with HLA-DRB1 ${ }^{\star} 0301$ (DR3) gene. J Exp Med (1996) 184:1167-72. doi:10.1084/jem.184.3.1167

27. Jacob JB, Kong YM, Meroueh C, Snower DP, David CS, Ho Y-S, et al. Control of Her-2 tumor immunity and thyroid autoimmunity by $\mathrm{MHC}$ and regulatory T cells. Cancer Res (2007) 67:7020-7. doi:10.1158/0008-5472.CAN06- 4755

28. Lewis M, Giraldo AA, Kong YM. Resistance to experimental autoimmune thyroiditis induced by physiologic manipulation of thyroglobulin level. Clin Immunol Immunopathol (1987) 45:92-104. doi:10.1016/0090-1229(87) 90115-2

29. Kari S, Flynn JC, Zulfiqar M, Snower DP, Elliott BE, Kong YM. Enhanced autoimmunity associated with induction of tumor immunity in thyroiditis-susceptible mice. Thyroid (2013) 23:1590-9. doi:10.1089/thy.2013.0064

30. Caturegli P, Lupi I, Landek-Salgado M, Kimura H, Rose NR. Pituitary autoimmunity: 30 years later. Autoimmun Rev (2008) 7:631-7. doi:10.1016/j.autrev. 2008.04.016

31. Maker AV, Yang JC, Sherry RM, Topalian SL, Kammula US, Royal RE, et al. Intrapatient dose escalation of anti-CTLA-4 antibody in patients with metastatic melanoma. J Immunother (2006) 29:455-63. doi:10.1097/01.cji.0000208259. 73167.58

32. Eggermont AM, Spatz A, Robert C. Cutaneous melanoma. Lancet (2014) 383:816-27. doi:10.1016/S0140-6736(13)60802-8

33. Landek-Salgado MA, Leporati P, Lupi I, Geis A, Caturegli P. Growth hormone and proopiomelanocortin are targeted by autoantibodies in a patient with biopsy-proven IgG4-related hypophysitis. Pituitary (2012) 15:412-9. doi:10. 1007/s11102-011-0338-8

34. Smith CJ, Bensing S, Burns C, Robinson PJ, Kasperlik-Zaluska AA, Scott RJ, et al. Identification of TPIT and other novel autoantigens in lymphocytic hypophysitis: immunoscreening of a pituitary cDNA library and development of immunoprecipitation assays. Eur J Endocrinol (2012) 166:391-8. doi:10.1530/EJE-11-1015

35. Lupi I, Raffaelli V, Di Cianni G, Caturegli P, Manetti L, Ciccarone AM, et al. Pituitary autoimmunity in patients with diabetes mellitus and other endocrine disorders. J Endocrinol Invest (2013) 36:127-31. doi:10.1007/BF03346747

36. Huang RR, Jalil J, Economou JS, Chmielowski B, Koya RC, Mok S, et al. CTLA4 blockade induces frequent tumor infiltration by activated lymphocytes regardless of clinical responses in humans. Clin Cancer Res (2011) 17:4101-9. doi:10.1158/1078-0432.CCR-11-0407 
37. Weber JS, Hamid O, Chasalow SD, Wu DY, Parker SM, Galbraith S, et al. Ipilimumab increases activated $\mathrm{T}$ cells and enhances humoral immunity in patients with advanced melanoma. J Immunother (2012) 35:89-97. doi:10.1097/CJI. 0b013e31823aa41c

38. Yuan J, Gnjatic S, Li H, Powel S, Gallardo HF, Ritter E, et al. CTLA-4 blockade enhances polyfunctional NY-ESO-1 specific T cell responses in metastatic melanoma patients with clinical benefit. Proc Natl Acad Sci U S A (2008) 105:20410-5. doi:10.1073/pnas.0810114105

39. Yuan J, Adamow M, Ginsberg BA, Rasalan TS, Ritter E, Gallardo HF, et al. Integrated NY-ESO-1 antibody and CD8 ${ }^{+}$T-cell responses correlate with clinical benefit in advanced melanoma patients treated with ipilimumab. Proc Natl Acad Sci U S A (2011) 108:16723-8. doi:10.1073/pnas.1110814108

40. Goff SL, Robbins PF, El-Gamil M, Rosenberg SA. No correlation between clinical response to CTLA-4 blockade and presence of NY-ESO-1 antibody in patients with metastatic melanoma. J Immunother (2009) 32:884-5. doi:10.1097/CJI. 0b013e3181affbfo

41. Hodi FS, O’Day SJ, McDermott DF, Weber RW, Sosman JA, Haanen JB, et al. Improved survival with ipilimumab in patients with metastatic melanoma. N Engl J Med (2010) 363:711-23. doi:10.1056/NEJMoa1003466

42. Venuprasad K, Kong YM, Farrar MA. Control of Th2-mediated inflammation by regulatory T cells. Am J Pathol (2010) 177:525-31. doi:10.2353/ajpath.2010. 090936

43. Simpson TR, Li F, Montalvo-Ortiz W, Sepulveda MA, Bergerhoff K, Arce F, et al. Fc-dependent depletion of tumor-infiltrating regulatory $\mathrm{T}$ cells co-defines the efficacy of anti-CTLA-4 therapy against melanoma. J Exp Med (2013) 210:1695-710. doi:10.1084/jem.20130579

44. Zitvogel L, Tanchot C, Granier C, Tartour E. Following up tumor-specific regulatory T cells in cancer patients. Oncoimmunology (2013) 2:e25444. doi:10.4161/ onci. 25444

45. Walter S, Weinschenk T, Stenzl A, Zdrojowy R, Pluzanska A, Szczylik C, et al. Multipeptide immune response to cancer vaccine IMA901 after single-dose cyclophosphamide associates with longer patient survival. Nat Med (2012) 18:1254-61. doi:10.1038/nm.2883

46. Bonertz A, Weitz J, Pietsch DH, Rahbari NN, Schlude C, Ge Y, et al. Antigenspecific Tregs control $\mathrm{T}$ cell responses against a limited repertoire of tumor antigens in patients with colorectal carcinoma. J Clin Invest (2009) 119:3311-21. doi:10.1172/JCI39608

47. Jandus C, Bioley G, Dojcinovic D, Derre L, Baitsch L, Wieckowski S, et al. Tumor antigen-specific FOXP3 + CD4 T cells identified in human metastatic melanoma: peptide vaccination results in selective expansion of Th1-like counterparts. Cancer Res (2009) 69:8085-93. doi:10.1158/0008-5472.CAN-09-2226

48. Schmidt HH, Ge Y, Hartmann FJ, Conrad H, Klug F, Nittel S, et al. HLA Class II tetramers reveal tissue-specific regulatory $\mathrm{T}$ cells that suppress $\mathrm{T}$ cell responses in breast carcinoma patients. Oncoimmunology (2013) 2:e24962. doi:10.4161/onci.24962

49. Wherry EJ. T cell exhaustion. Nat Immunol (2011) 12:492-9. doi:10.1038/ni. 2035

50. Intlekofer AM, Thompson CB. At the bench: preclinical rationale for CTLA-4 and PD-1 blockade as cancer immunotherapy. J Leukoc Biol (2013) 94:25-39. doi:10.1189/jlb.1212621

51. Callahan MK, Wolchok JD. At the bedside: CTLA-4- and PD-1-blocking antibodies in cancer immunotherapy. J Leukoc Biol (2013) 94:41-53. doi:10.1189/ jlb.1212631

52. Ahmadzadeh M, Johnson LA, Heemskerk B, Wunderlich JR, Dudley ME, White $\mathrm{DE}$, et al. Tumor antigen-specific CD8 $\mathrm{T}$ cells infiltrating the tumor express high levels of PD-1 and are functionally impaired. Blood (2009) 114:1537-44. doi:10.1182/blood-2008-12-195792

53. Wang W, Lau R, Yu D, Zhu W, Korman A, Weber J. PD1 blockade reverses the suppression of melanoma antigen-specific CTL by $\mathrm{CD} 4{ }^{+} \mathrm{CD} 25^{\mathrm{Hi}}$ regulatory $\mathrm{T}$ cells. Int Immunol (2009) 21:1065-77. doi:10.1093/intimm/dxp072

54. Velcheti V, Schalper KA, Carvajal DE, Anagnostou VK, Syrigos KN, Sznol M, et al. Programmed death ligand-1 expression in non-small cell lung cancer. Lab Invest (2014) 94:107-16. doi:10.1038/labinvest.2013.130

55. Topalian SL, Hodi FS, Brahmer JR, Gettinger SN, Smith DC, McDermott DF, et al. Safety, activity, and immune correlates of anti-PD-1 antibody in cancer. N Engl J Med (2012) 366:2443-54. doi:10.1056/NEJMoa1200690
56. Nishimura H, Nose M, Hiai H, Minato N, Honjo T. Development of lupus-like autoimmune diseases by disruption of the PD-1 gene encoding an ITIM motifcarrying immunoreceptor. Immunity (1999) 11:141-51. doi:10.1016/S10747613(00)80089-8

57. Okazaki T, Tanaka Y, Nishio R, Mitsuiye T, Mizoguchi A, Wang J, et al. Autoantibodies against cardiac troponin I are responsible for dilated cardiomyopathy in PD-1-deficient mice. Nat Med (2003) 9:1477-83. doi:10.1038/nm955

58. PD-1 inhibitor becomes "breakthrough therapy". Cancer Discov (2013) 3:OF14. doi:10.1158/2159-8290.CD-NB2013-074

59. Hamid O, Robert C, Daud A, Hodi FS, Hwu WJ, Kefford R, et al. Safety and tumor responses with lambrolizumab (anti-PD-1) in melanoma. $N$ Engl J Med (2013) 369:134-44. doi:10.1056/NEJMoa1305133

60. Kyi C, Postow MA. Checkpoint blocking antibodies in cancer immunotherapy. FEBS Lett (2014) 588:368-76. doi:10.1016/j.febslet.2013.10.015

61. Topalian SL, Sznol M, McDermott DF, Kluger HM, Carvajal RD, Sharfman WH, et al. Survival, durable tumor remission, and long-term safety in patients with advanced melanoma receiving nivolumab. J Clin Oncol (2014) 32:1020-30. doi:10.1200/JCO.2013.53.0105

62. Brahmer JR, Tykodi SS, Chow LQ, Hwu WJ, Topalian SL, Hwu P, et al. Safety and activity of anti-PD-L1 antibody in patients with advanced cancer. $N$ Engl J Med (2012) 366:2455-65. doi:10.1056/NEJMoa1200694

63. Latchman Y, Wood CR, Chernova T, Chaudhary D, Borde M, Chernova I, et al. PD-L2 is a second ligand for PD-1 and inhibits T cell activation. Nat Immunol (2001) 2:261-8. doi:10.1038/85330

64. Tseng SY, Otsuji M, Gorski K, Huang X, Slansky JE, Pai SI, et al. B7-DC, a new dendritic cell molecule with potent costimulatory properties for T cells. J Exp Med (2001) 193:839-46. doi:10.1084/jem.193.7.839

65. Fife BT, Pauken KE, Eagar TN, Obu T, Wu J, Tang Q, et al. Interactions between PD-1 and PD-L1 promote tolerance by blocking the TCR-induced stop signal. Nat Immunol (2009) 10:1185-92. doi:10.1038/ni.1790

66. Curran MA, Montalvo W, Yagita H, Allison JP. PD-1 and CTLA-4 combination blockade expands infiltrating $\mathrm{T}$ cells and reduces regulatory $\mathrm{T}$ and myeloid cells within B16 melanoma tumors. Proc Natl Acad Sci U S A (2010) 107:4275-80. doi:10.1073/pnas.0915174107

67. Duraiswamy J, Kaluza KM, Freeman GJ, Coukos G. Dual blockade of PD-1 and CTLA-4 combined with tumor vaccine effectively restores T-cell rejection function in tumors. Cancer Res (2013) 73:3591-603. doi:10.1158/0008-5472.CAN$12-4100$

68. Holmgaard RB, Zamarin D, Munn DH, Wolchok JD, Allison JP. Indoleamine 2,3dioxygenase is a critical resistance mechanism in antitumor $\mathrm{T}$ cell immunotherapy targeting CTLA-4. J Exp Med (2013) 210:1389-402. doi:10.1084/jem. 20130066

69. Leach DR, Krummel MF, Allison JP. Enhancement of antitumor immunity by CTLA-4 blockade. Science (1996) 271:1734-6. doi:10.1126/science.271.5256. 1734

70. Read S, Malmström V, Powrie F. Cytotoxic T lymphocyte-associated antigen 4 plays an essential role in the function of $\mathrm{CD} 25^{+} \mathrm{CD} 4^{+}$regulatory cells that control intestinal inflammation. J Exp Med (2000) 192:295-302. doi:10.1084/jem.192.2.295

71. Hurwitz AA, Foster BA, Kwon ED, Truong T, Choi EM, Greenberg NM, et al. Combination immunotherapy of primary prostate cancer in a transgenic mouse model using CTLA-4 blockade. Cancer Res (2000) 60:2444-8.

72. Ansari MJI, Salama AD, Chitnis T, Smith RN, Yagita H, Akiba H, et al. The programmed death-1 (PD-1) pathway regulates autoimmune diabetes in nonobese diabetic (NOD) mice. J Exp Med (2003) 198:63-9. doi:10.1084/jem. 20022125

73. Kwidzinski E, Bunse J, Aktas O, Richter D, Mutlu L, Zipp F, et al. Indolamine 2,3dioxygenase is expressed in the CNS and down-regulates autoimmune inflammation. FASEB J (2005) 19:1347-9. doi:10.1096/fj.04-3228fje

74. Ruocco MG, Pilones KA, Kawashima N, Cammer M, Huang J, Babb JS, et al. Suppressing $\mathrm{T}$ cell motility induced by anti-CTLA-4 monotherapy improves antitumor effects. J Clin Invest (2012) 122:3718-30. doi:10.1172/ JCI61931

75. Liu $\mathrm{H}, \mathrm{Hu} \mathrm{B}, \mathrm{Xu} \mathrm{D}$, Liew FY. $\mathrm{CD} 4{ }^{+} \mathrm{CD} 25^{+}$regulatory $\mathrm{T}$ cells cure murine colitis: the role of IL-10, TGF- $\beta$, and CTLA4. J Immunol (2003) 171:5012-7. doi:10.4049/jimmunol.171.10.5012 
76. Oaks MK, Hallett KM. Cutting edge: a soluble form of CTLA-4 in patients with autoimmune thyroid disease. J Immunol (2000) 164:5015-8. doi:10.4049/ jimmunol.164.10.5015

77. Choi JM, Kim SH, Shin JH, Gibson T, Yoon BS, Lee DH, et al. Transduction of the cytoplasmic domain of CTLA-4 inhibits TcR-specific activation signals and prevents collagen-induced arthritis. Proc Natl Acad Sci U S A (2008) 105:19875-80. doi:10.1073/pnas.0805198105

78. Hurwitz AA, Sullivan TJ, Krummel MF, Sobel RA, Allison JP. Specific blockade of CTLA-4/B7 interactions results in exacerbated clinical and histologic disease in an actively-induced model of experimental allergic encephalomyelitis. J Neuroimmunol (1997) 73:57-62.

79. Fife BT, Bluestone JA. Control of peripheral T-cell tolerance and autoimmunity via the CTLA-4 and PD-1 pathways. Immunol Rev (2008) 224:166-82. doi:10.1111/j.1600-065X.2008.00662.x

80. Wolchok JD, Kluger H, Callahan MK, Postow MA, Rizvi NA, Lesokhin AM, et al. Nivolumab plus ipilimumab in advanced melanoma. N Engl J Med (2013) 369:122-33. doi:10.1056/NEJMoa1302369
Conflict of Interest Statement: The authors declare that the research was conducted in the absence of any commercial or financial relationships that could be construed as a potential conflict of interest.

Received: 11 February 2014; accepted: 25 April 2014; published online: 16 May 2014. Citation: Kong YM and Flynn JC (2014) Opportunistic autoimmune disorders potentiated by immune-checkpoint inhibitors anti-CTLA-4 and anti-PD-1. Front. Immunol. 5:206. doi: 10.3389/fimmu.2014.00206

This article was submitted to Tumor Immunity, a section of the journal Frontiers in Immunology.

Copyright (C) 2014 Kong and Flynn. This is an open-access article distributed under the terms of the Creative Commons Attribution License (CC BY). The use, distribution or reproduction in other forums is permitted, provided the original author(s) or licensor are credited and that the original publication in this journal is cited, in accordance with accepted academic practice. No use, distribution or reproduction is permitted which does not comply with these terms. 